\title{
Features of Terra Firma-Forme Dermatosis
}

Nurşad Çifci Aslan, MD

Şükran Güler, $M D^{2}$

Kamile Demirci, $M D^{3}$

Emel Istyel, $M D^{4}$

'Department of Dermatology, Kocaeli Derince Education and Research Hospital, Kocaeli, Turkey

${ }^{2}$ Department of Pediatrics, Kocaeli Derince Education and Research Hospital, Kocaeli, Turkey

${ }^{3}$ Department of Dermatology, Gölcük Necati Çelik State Hospital, Kocaeli, Turkey

${ }^{4}$ Department of Pediatric Nephrology, Kocaeli Derince Education and Research Hospital, Kocaeli, Turkey

Conflict of interest: authors report none.

\section{CORRESPONDING AUTHOR}

Nurşad Çifci Aslan, MD

Department of Dermatology

Kocaeli Derince Education and Research

Hospital

Kocaeli Üniversitesi Umuttepe Yerleşkesi 41380, Kocaeli, Turkey

nuradaslan@yahoo.com

\begin{abstract}
Terra-firma-forme dermatosis (TFFD) is a little known hyperpigmented skin disease that is more common than expected. We examined retrospectively the medical records of 79 patients: $88.6 \%$ were children, the mean age was 10.4 years ( $S D=7.5$ years), and $64.6 \%$ were female. The dermatoses were found on the trunk in $27.8 \%$, extremities in $26.6 \%$, fold zones in $8.9 \%$, and head in $2.5 \%$ of the patients. The lesions appeared in more than 1 location in $34.2 \%$ of the patients and were symmetrically located $77.2 \%$ of the time. Swabbing with alcohol is sufficient for diagnosis and treatment. TFFD, mostly seen in children and female patients, should be kept in mind to avoid unnecessary diagnostic testing and treatment.
\end{abstract}

Ann Fam Med 2018;16:52-54. https://doi.org/10.1370/afm.2175

\section{INTRODUCTION}

$\mathrm{T}$ erra firma-forme dermatosis (TFFD) was first described in 1987 as Duncan's dirty dermatitis. ${ }^{1}$ Terra firma-forme means dirty, dry surface in Latin, but in TFFD the patients practice good hygiene. The lesions appear as brown-gray pigmented plaques and patches and can feel rough when palpated. TFFD does not cause any symptoms. Disappearance of the lesions by rubbing with $70 \%$ isopropyl alcohol is diagnostic for disease. ${ }^{1-7}$

TFFD can be easily diagnosed and treated, but if the physician does not consider it early in the diagnosis, unnecessary diagnostic and treatment procedures may result. In this study, we aimed to evaluate the demographic and clinical features of the TFFD.

\section{METHODS}

We evaluated retrospectively the medical records of patients with a diagnosis of TFFD between June 2013 and February 2016. Demographic features, dermatological findings, and accompanying systemic and dermatological diseases were documented. We received ethical approval from the ethics committee of Kocaeli University. Informed consent was obtained from all individual participants included in the study.

\section{RESULTS}

There were 79 patients with TFFD 70 were children (aged 1 to 17 years), and 9 were adult (aged 18 to 42 years). Fifty-one (65.6\%) of the patients were female (Table 1). Accompanying dermatological diseases and systemic diseases are displayed in Table 1.

Location of the lesions is displayed in Table 2. In $34.2 \%$ of cases lesions were found in more than 1 area of the body. They appeared on the trunk, extremities, folded zones, and head and neck in decreasing order. The lesions were symmetrically distributed in $61(77.2 \%)$ patients.

The lesions disappeared after being wiped with $70 \%$ isopropyol alcohol-soaked gauze, as shown in Supplemental Figures 1 and 2 (available at: http://AnnFamMed.org/content/16/1/52/suppl/DC1). 


\section{DISCUSSION}

TFFD is a keratinization disorder with an asymptomatic dirt-like appearance that occurs despite adequate hygiene. It should be differentiated from dermatosis neglecta, acanthosis nigricans, neurodermatitis, ichthyosis, pityriasis versicolor, epidermal nevi, and confluent and reticulated papillomatosis. ${ }^{1-12}$ The lesions can be mistaken for dirt, even though the patient's hygiene is good. The dirt-like lesions make patients and their parents uncomfortable; they report, "We are constantly washing these places with soap." In addition to the

Table 1. Demographic and Clinical Features of Patients

\begin{tabular}{lc}
\hline Characteristic & Value \\
\hline Demographic & \\
Total patients, No. & 79 \\
$\quad$ Child, No. (\%) & $70(88.6)$ \\
Adult, No. (\%) & $9(11.4)$ \\
Age, y, mean (SD) & $10.4(7.5)$ \\
Sex & \\
Female, No. (\%) & $51(64.6)$ \\
Male, No. (\%) & $28(35.4)$ \\
Pediatric, female, No. (\%) & $44(62.9)$ \\
Pediatric, male, No. (\%) & $26(37.1)$ \\
Adult, female, No. (\%) & $7(77.8)$ \\
Adult, male, No. (\%) & $2(22.2)$ \\
Accompanying skin disease & \\
Atopic dermatitis, No. (\%) & $6(7.6)$ \\
Ketosis, No. (\%) & $23(29.1)$ \\
Acne, No. (\%) & $3(3.8)$ \\
Rosacea, No. (\%) & $1(1.3)$ \\
Seborrheic dermatitis, No. (\%) & $1(1.3)$ \\
Vitiligo, No. (\%) & $1(1.3)$ \\
Other accompanying disease & \\
Allergic rhinitis/allergic asthma, No. (\%) & $9(11.4)$ \\
Urinary tract infection, No. (\%) & $5(6.3)$ \\
Malignancy (osteosarcoma and chronic & $2(2.5)$ \\
myeloid leukemia), No. (\%) & $2(2.5)$ \\
Hypothyroidism, No. (\%) & \\
\hline
\end{tabular}

Table 2. Location of Lesions

\begin{tabular}{lc}
\hline Location & No. (\%) \\
\hline Trunk & $22(27.8)$ \\
Extremity & $21(26.6)$ \\
Folded zone & $7(8.9)$ \\
Head (face and ears) & $2(2.5)$ \\
More than 1 region & $27(34.2)$ \\
Entire body & $7(8.9)$ \\
Arms and trunk & $6(7.6)$ \\
Legs and trunk & $8(10.1)$ \\
Head, neck, and trunk & $6(7.6)$ \\
Symmetrical distribution & $61(77.2)$ \\
\hline
\end{tabular}

parents' observation, when examining the patient, the physician can differentiate the lesions from dermatosis neglecta and real dirt.

Aggressive diagnostic and therapeutic approaches can result when the physician does not recognize TFFD. For example, a skin biopsy was taken from a girl with a presumed diagnosis of ichthyosis vulgaris (Supplemental Figure 1). Before arrival at our clinic, another patient was believed to have pityriasis versicolor, and treatment was attempted using antifungal medication.

The exact cause of TFFD is still unclear. Histopathological studies are limited, but lamellar hyperkeratosis, compact orthokeratosis with whorls, keratin globules in the stratum corneum, increased melanin, and Malassezia furfur spores in the basal layer have been reported. ${ }^{2-6}$ The clinical appearance of TFFD may be explained by an abnormal keratinization and accumulation of melanin and dirt within the epidermis. Further histopathologic studies, however, may be useful in terms of illuminating the etiopathogenesis of the disease.

Genetic predisposition has been mentioned in previous case reports. ${ }^{1-12}$ In our study group, 2 patients were siblings and had xerosis. This finding suggests a genetic predisposition, but wider studies are needed to address this possibility.

Emollients and sun exposure have also been reported as causative factors. ${ }^{3,4}$ Because our patients reported no history of regular emollient use, even those with atopic dermatitis and keratosis, we believe that emollient usage is not a causative factor. There may be a relationship between TFFD and xerosis, which is also a disorder of keratinization. Our patients had lesions in places that were not exposed to the sun, which would suggest there is no relationship between sun exposure and TFFD.

Some patients had acne, seborrheic dermatitis, rosacea, and vitiligo, but the locations of the TFFD lesions were different from where these lesions were found. According to our results, there may be no relationship between these dermatoses and TFFD. Further studies about accompanying skin diseases may be informative about the etiopathogenesis of TFFD.

A total of 18 patients had other systemic diseases, such as allergic rhinitis, allergic asthma, urinary tract infection, hypothyroidism, osteosarcoma, and chronic myeloid leukemia. There is no report describing the relation of these diseases with TFFD. Future studies may be useful to determine whether other systemic diseases are related TFFD.

In previous case reports, lesions were found to be mostly on skin folds. ${ }^{1-12}$ In our study, more than 1 anatomical region was involved. Lesions were found on the trunk, extremities, skin folds (neck, axilla, inguinal region, umbilical fold), and face in decreasing order. 
TFFD has been reported to affect both sexes equally and affect all age-groups, though mostly children. ${ }^{1-12}$ In our study, most of our patients were children and female. Women take more care about their appearance and are more likely to notice these lesions on themselves. Even so, most of our patients were children, and the lesions had been noticed by the parents. The predominance of female patients therefore cannot be related to a tendency of women to notice TFFD lesions. Studies about predominance of TFFD in female patients may be useful in further understanding the etiopathogenesis of this disease.

In previous cases reports, recurrence was not reported. ${ }^{1-12}$ Our findings were similar; during a period of 19 months, no recurrence was seen. Even so, 5 patients reported a history of recurrence, and we believe there may have been more recurrences than we evaluated. When lesions reappeared, patients may have cleaned them with isopropyl alcohol and chose not return to our clinic.

TFFD is predominantly a childhood dermatosis, mostly seen in female patients, and it may be more common than expected. Wiping the lesions with alcohol is both diagnostic and therapeutic. TFFD should be kept in mind in the differential diagnosis of hyperpigmented and hyperkeratotic lesions to avoid unnecessary diagnostic testing and therapeutic treatments.

To read and post commentaries in response to this article, see it online at http://www.AnnFamMed.org/content/16/1/52.

Key words: primary health care; dermatosis, children; isopropyl alcohol; terra firma-forme

Submitted January 23, 2017; submitted, revised, April 3, 2017; accepted May 3, 2017.

Ethical approval: All procedures performed in studies involving human participants were in accordance with the ethical standards of the institutional and/or national research committee and with the 1964 Helsinki declaration and its later amendments or comparable ethical standards.
Author contributions: N.C..A. was responsible for the idea for research, planning the methods, organization of the project and manuscript preparation, management of patients, organizing and reporting data, presentation and logical explanation of results, conducting literature searches, creation of entire part of manuscript, writing and checking all manuscript; K.D. took part in the literature search and preparation of references; Ş.G., K.D., and E.I. took part in the management of the patients.

Supplementary materials: Available at http://www.AnnFamMed. org/content/16/1/52/suppl/DC1/.

\section{References}

1. Duncan WC, Tschen JA, Knox JM. Terra firma-forme dermatosis. Arch Dermatol. 1987;123(5):567-569.

2. Browning J, Rosen T. Terra firma-forme dermatosis revisited. Dermatol Online J. 2005;11(2):15.

3. Erkek E, Sahin S, Çetin ED, Sezer E. Terra firma-forme dermatosis. Indian J Dermatol Venereol Leprol. 2012;78(3):358-360.

4. Babu AR, Vijayashankar M. Terra firma-formedermatosis: a case report. Our Dermatol Online. 2013;4(1):89-90.

5. Sezgin AÖ, Gerçeker Türk B, Yaman B, DereliT. [Terra firma-forme dermatosis]. Türkderm 2013;47(3):187-9.

6. Akkash L, Badran D, Al-Omari AQ. Terra Firma forme dermatosis. Case series and review of the literature. J Dtsch Dermatol Ges. 2009; 7(2):102-107.

7. Berk DR. Terra firma-forme dermatosis: a retrospective review of 31 patients. Pediatr Dermatol. 2012;29(3):297-300.

8. Thomas RS, Collins J, Young RJ, Bohlke A. Atypical presentations of terra firma-forme dermatosis. Pediatr Dermatol. 2015;32(2):e50-e53.

9. Tavlı YU, Mevlitoğlu I, Toy H, Unal M. Terra firma forme disease. J Paediatr Child Health. 2012;48(11):1046-1047.

10. Berk DR, Mutizwa MM. Comment regarding the histopathology of terra firma-forme dermatosis. J Cutan Pathol. 2012;39(2):300-301, author reply 302-303.

11. Guarneri C, Guarneri F, Cannavò SP. Terra firma-forme dermatosis. Int J Dermatol. 2008;47(5):482-484.

12. Greywal T, Cohen PR. Terra firma-forme dermatosis: a report of ten individuals with Duncan's dirty dermatosis and literature review. Dermatol Pract Concept. 2015;5(3):29-33. Published online 2015 Jul 31. 